Human Capital and Economic Opportunity: A Global Working Group

Working Paper Series

Working Paper No. 2012-020

\title{
Early Life Adversity and Children's Competence Development: Evidence from the Mannheim Study of Children at Risk
}

Dorothea Blomeyer

Katja Coneus

Manfred Laucht

Friedhelm Pfeiffer

October, 2012

Human Capital and Economic Opportunity Working Group Economic Research Center University of Chicago 1126 E. 59th Street 


\title{
Early life adversity and children's competence development:
} evidence from the Mannheim Study of Children at Risk

\author{
Dorothea Blomeyer*, Katja Coneus**, Manfred Laucht*, Friedhelm Pfeiffer*** \\ * Central Institute of Mental Health (ZI), Mannheim \\ ** SAP, Walldorf \\ *** Centre for European Economic Research (ZEW), Mannheim
}

October 15, 2012

This paper investigates the role of early life adversity and home resources in terms of competence formation and school achievement based on data from an epidemiological cohort study following 364 children from birth to adolescence. Results indicate that organic and psychosocial risks present in early life as well as the socio-emotional home environment are significant predictors for the formation of competencies. Competencies acquired at preschool age predict achievement at school age. A counterfactual analysis is performed to assess trade-offs in the timing of interventions in the early life cycle.

Keywords: Initial Risk Matrix, Socio-Emotional and Economic Home Resources, Intelligence, Persistence, Peer Relationship, School Achievement

JEL-Classification: D87, I12, I21, J13

\section{Acknowledgements:}

We gratefully acknowledge generous support from the Leibniz Association (LA), Bonn, through the grant "Non-cognitive Skills: Acquisition and Economic Consequences". Dorothea Blomeyer and Manfred Laucht thank the German Research Foundation (DFG9 and the Federal Ministry of Education and Research (BMBF) for their support in conducting the Mannheim Study of Children at Risk. The views expressed in this article are those of the authors and do not necessarily reflect the views of the LA, the BMBF or the DFG. For helpful discussions, we thank Anja Achtziger, Lex Borghans, Liam Delaney, Bart Golsteyn, James Heckman, Winfried Pohlmeier, Petra Todd, the editor of the Journal of Economics and Statistics and two referees. For competent research assistance, we are grateful to Marianella Gonzalez, Moritz Meyer and Julia Schäfer. All opinions and mistakes are our own.

\section{Corresponding author:}

Friedhelm Pfeiffer, Centre for European Economic Research (ZEW), P.O. Box 103443, D-68034 Mannheim. Tel.: +49-621-1235-150, E-mail: pfeiffer@zew.de 


\section{Introduction}

Competencies are formed in a dynamic and cumulative process between adult caregivers and children through a series of development transitions. There is a burgeoning economic literature using psychological data from infancy to understand the role of the initial risk matrix and early home environment for later development (Blomeyer et al., 2009, Cunha et al., 2010, Currie, 2011, Heckman, 2007, Pfeiffer and Reuß, 2008, Spieß, 2011, among others).

We contribute to this multidisciplinary research by employing unique data from a developmental psychological approach, the Mannheim Study of Children at Risk, abbr. MARS (derived from the German title of the study: "Mannheimer Risikokinder $\underline{\text { Stud- }}$ ie”). MARS is an epidemiological cohort study that follows a carefully selected group of children from birth to adulthood. Children at risk are oversampled in the data. This is an advantage for our purpose since the total sample covers the full range of early life adversity stemming from the initial risk matrix, be it organic or psychosocial in nature (see Blomeyer et al., 2009, Coneus et al., 2012, Laucht et al., 2004). In addition, the data contain a unique set of psychological expert ratings on stage-specific competencies and the home environment in significant stages of development. ${ }^{1}$ This peerless data feature improves the chance to uncover the key role of early interaction for human capital formation.

The contribution to the literature is an initial assessment of trade-offs in the timing of interventions at different development stages to foster social achievement. We extend our previous work in three further directions. First, the socio-emotional home environ-

\footnotetext{
${ }^{1}$ Infancy, toddlerhood, preschool age, elementary school age, secondary school age.
} 
ment is measured with the wide-spread original Home Observatory for Measurement of the Environment (HOME) (Caldwell and Bradley, 1984) for the first time. The findings are compared with our previous study, Blomeyer et al. (2009), where a modified version of the HOME was utilized, enriched with information on mother-child interaction during early childhood. Second, we investigate the role of basic preschool competencies for further social outcomes such as interests and peer relationships. Third, we elaborate on gender differences in competence formation.

Our results demonstrate that interpersonal differences in competencies are consistently associated with early life adversity and the socio-emotional home environment, with the relationship being specific to age and competencies. Children are exposed to a matrix of organic and psychosocial risks, and each factor by itself contributes to their development as well as the sum of all factors. We conclude that advantages from beneficial socio-emotional environments and disadvantages from adverse environments cumulate during the developmental course. Thus, disadvantages in early childhood that impair development persist and affect competence formation further during later childhood. There is evidence for synergies and dynamic complementarities in the formation of competencies and social outcomes. The counterfactual policy analysis suggests that socio-emotional and economic support for disadvantaged children needs to be extended continuously and stage-specifically.

The usage of the original instead of the modified HOME does not change these conclusions. The association between the home environment and the competencies remains significant although the estimated coefficients are slightly lower when the original HOME is utilized. Gender seems to play no or only a moderate role in competence formation over the early life cycle. 
Our work is related to Cunha et al. (2010), who use a sample of 2,207 first-born white children from the Children of the National Longitudinal Survey of Youth (CNLSY). They estimate the "technology of skill formation" for two developmental stages (0 to 5 or 6,5 or 6 to 13 or 14 years) and two competencies (cognitive, non-cognitive). Factor models are employed to deal with the issue of measurement error in inputs and outputs, which seem to be a serious problem in their data. In our study, we rely on the developmental psychological approach and the epidemiological expert ratings and compare two measures of the home environment. Although Cunha et al. (2010) consider only two developmental stages and the methodology and the data differ, our results seem to be more similar than diverse compared to their findings. Future research is needed to examine the issues related to the methods of measuring competencies and the home environment in different data in further detail.

Our results with respect to early life adversity contribute to recent findings on long-term outcomes of inequality at birth (see Currie, 2011), often measured with birth weight (Black et al., 2007, among others). According to our analysis, neonatal complications, adverse psychosocial conditions like maternal discord, low-skilled parents, overcrowding and other factors from the initial risk matrix (introduced in the next section) may impair development of human capital in addition to birth weight.

The paper is organized as follows. Section 2 introduces the epidemiological cohort study and the measurement of competencies and the home environment. Section 3 discusses the estimates of the stage specific technology of competence formation. In Section 4, complementarities between basic competencies in childhood and social and academic achievement at school age are analyzed. Section 5 assesses alternative intervention policies during the early life course, and Section 6 concludes. 


\section{The Mannheim Study of Children at Risk}

The MARS project follows a cohort of infants to examine the impact of initial adverse conditions on the prevalence of later developmental disorders and negative social outcomes (Laucht et al., 1997, 2004). ${ }^{2}$ Infants were recruited from two obstetric and six children's hospitals in the Rhine-Neckar region of Germany. Children with severe physical handicaps, obvious genetic defects or metabolic diseases were excluded. The initial participation rate was 64.5 percent, with a slightly lower rate in families from low socio-economic backgrounds. To control for confounding effects related to home resources and the infant's medical status, only first-born children with singleton births to German-speaking parents of predominantly (> 99.0 percent) European descent, born between February 1986 and February 1988, were enrolled.

The first 110 children were included consecutively into the study, irrespective of riskgroup status. These children form our approximate normative sample. To separate the independent and combined effects of organic and psychosocial risks on child development, infants were rated according to the degree of "organic" risk and the degree of "psychosocial" risk. After the exclusion of 18 children with severe handicap 364 chil-

\footnotetext{
${ }^{2}$ We do not investigate developmental disorders in the current study. Laucht et al. (2002, 2004) demonstrated that the negative impact of early life adversity persisted into late childhood. Rates of developmental and behavioral disorders in high-risk children were up to three times higher than in non-risk children. Both organic and psychosocial risks contributed to adverse outcomes. While organic complications were related to disorders in motor and cognitive development, the detrimental effects of psychosocial adversity pertained to disorders in social-emotional functioning. The cumulative effect of early adversities was best explained by summing up the single risk effects. The SOEP mother-child questionnaires provide an additional data set that follows children from birth to adolescence (see Berger et al., 2011, Spieß, 2011). As a rule, children's competencies in these data are based on maternal assessments, not on expert ratings, with one recent exception summarized in Bartling et al. (2010) (see also Kosse and Pfeiffer, 2012). Based on experimental measures it is demonstrated that there is a positive association between mothers' and children’s impatience.
} 
dren (174 boys, 190 girls) that is 95 percent of the infants in the initial wave, remained for the analysis. In the current paper, only the first five research waves are used (see Figure 1) because the measurement of basic cognitive and motor competencies was conducted in these waves only. These basic competencies seem to consolidate around the age of ten years.

Psychometric assessments were conducted for the initial organic and psychosocial risk matrix. Each risk factor was scaled as either non risk, moderate risk or high risk, resulting in a 3x3 design (Figure 1). All groups are roughly equal in size, with a slight oversampling in the high-risk combinations. Sex is distributed evenly in all subgroups.

Figure 1: The matrix design of the Mannheim Study of Children at Risk

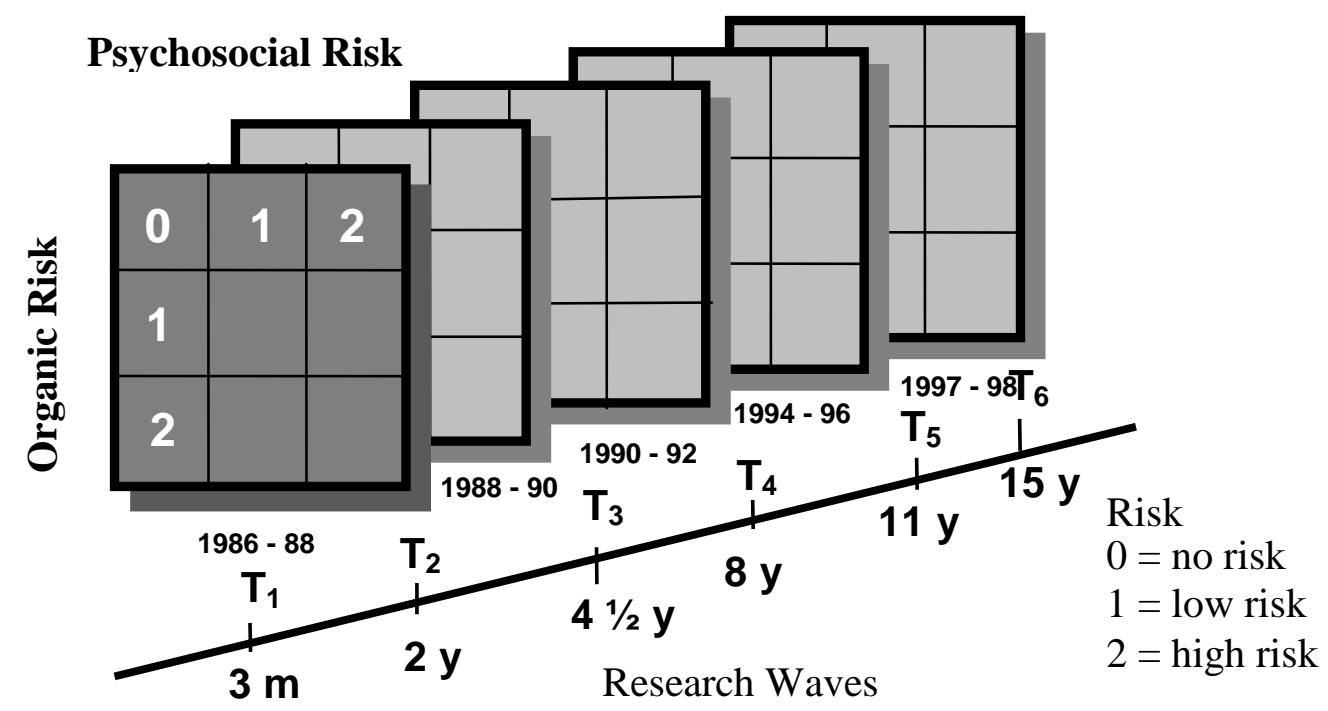

Source: Laucht et al. (2004).

Organic risk is determined by the degree of pre-, peri- or neonatal complications. The risk factors and their prevalence in the sample are shown in Table A1. Pre- and perinatal variables were extracted from maternal obstetric and infant neonatal records and are used for organic risk classification. Organic risk is classified as follows: 
1. The non-risk group consists of infants who were born full-term, had normal birth weight and no medical complications (items 1-4).

2. The moderate-risk group contains infants who had experienced premature births or premature labor, or pre-eclampsia of the mother but no severe complications (items $5-7)$.

3. The high-risk group comprises infants who had very low birth weight or a clear case of asphyxia with special care treatment or neonatal complications, such as seizures, respiratory therapy or sepsis (items 8-10).

Psychosocial risk is determined according to a risk index proposed by Rutter and Quinton (1977), which measures the presence of unfavorable family characteristics, for example marital discord or low-skilled parents. The "enriched" family adversity index includes eleven adverse family factors during a period of one year prior to birth, as reported in Table A2. Information on the psychosocial risk rating was taken from a standardized parent interview conducted at the research wave at infancy (three months assessment). Psychosocial risk is classified as follows:

1. The non-risk group includes infants who had none of the psychosocial risks.

2. The moderate-risk group contains infants with one or two of these factors.

3. The infants from the high-risk group came from a family dealing with 3 or more of these risk factors.

Throughout this paper, the expression “competencies” summarizes basic abilities of children, such as logical and verbal reasoning, or non-cognitive skills for instance persistence. In MARS, comprehensive psychometric assessments were conducted for competencies during infancy (three-month assessment), toddlerhood (two-year assessment), 
preschool age (assessment at four and a half years), elementary school age (assessment at the age of eight years) and secondary school age (assessment at the age of eleven years), representing significant stages of development.

The terms cognitive, motor, and non-cognitive competencies indicate three different, yet dependent, basic dimensions of human capability and are measured using psychometric methods (see Blomeyer et al., 2009). Cognitive competencies include memory capacity, information processing speed, linguistic and logic skills, and general problem-solving abilities (IQ). Motor competencies are assessed as fine and gross motor skills and body coordination (MQ). Our indicator of non-cognitive competencies is defined as persistence $(P)$. It measures the ability to pursue a particular activity and its continuation in the face of distractors and obstacles.

The expression "home environment" summarizes the economic, emotional, and social resources available for the child at home. There are two types of home environment variables used to assess the children's family living conditions, summarized under socio-emotional home environment, H (HOME score, Bradley, 1989, Bradley et al., 2000, Caldwell and Bradley, 1994), and one economic category, the monthly net income per household member, $Y$ (in real Euros, base year 1995). In comparison to our former study (Blomeyer et al., 2009) the home environment indicates the original HOME scales from Caldwell and Bradley (1984) without additional or enriched measures of mother-child interaction. A comparison of econometric findings shall help to improve our understanding of home resources and children's outcomes.

Both measures of a child's home resources $(H$ and $Y$ ) decline steadily along with the psychosocial risk dimension (Table 1). Within the group of children with high psychosocial risk, $Y$ is on average 67 percent of the value of the non-risk group in infancy. The 
differences in the average $H$ in the risk matrix show a similar pattern. For the group of children with high psychosocial risk, $H$ is 87 percent of that of the non-risk group.

Table 1: $H$ and $Y$ in children aged three months and eleven years evaluated in the risk matrix (means, standard deviations in parentheses)

\begin{tabular}{|c|c|c|c|c|c|c|c|}
\hline & & \multicolumn{6}{|c|}{ Psychosocial Risk } \\
\hline & & \multicolumn{2}{|c|}{ non-risk } & \multicolumn{2}{|c|}{ Moderate } & \multicolumn{2}{|c|}{ High } \\
\hline & & & & $H: H O N$ & score & & \\
\hline & & 3 months & 11 years & 3 months & 11 years & 3 months & 11 years \\
\hline \multirow{5}{*}{ 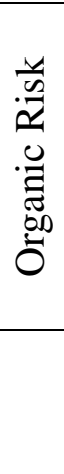 } & non-risk & $\begin{array}{r}106^{*} \\
(11.11)\end{array}$ & $\begin{array}{l}108^{*} \\
(6.9)\end{array}$ & $\begin{array}{c}102 * \\
(11.4)\end{array}$ & $\begin{array}{l}105^{*} \\
(9.8)\end{array}$ & $\begin{array}{r}93 \\
(18.2)\end{array}$ & $\begin{array}{r}91 \\
(19.5)\end{array}$ \\
\hline & moderate & $\begin{array}{c}105^{*} \\
(10.5)\end{array}$ & $\begin{array}{l}107 * \\
(7.3)\end{array}$ & $\begin{array}{r}101 \\
(13.9)\end{array}$ & $\begin{array}{r}99 \\
(12.8)\end{array}$ & $\begin{array}{r}91 \\
(17.9)\end{array}$ & $\begin{array}{r}93 \\
(21.0)\end{array}$ \\
\hline & high & $\begin{array}{l}108 * \\
(8.3)\end{array}$ & $\begin{array}{l}106^{*} \\
(9.6)\end{array}$ & $\begin{array}{c}102 * \\
(10.3)\end{array}$ & $\begin{array}{r}97 \\
(10.4)\end{array}$ & $\begin{array}{r}94 \\
(18.4)\end{array}$ & $\begin{array}{r}94 \\
(17.4)\end{array}$ \\
\hline & & \multicolumn{6}{|c|}{ Y: monthly net income per head (euros) } \\
\hline & & 3 months & 11 years & 3 months & 11 years & 3 months & 11 years \\
\hline \multirow{3}{*}{ 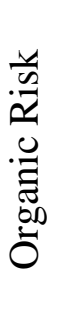 } & non-risk & $\begin{array}{l}812 * \\
(499)\end{array}$ & $\begin{array}{l}835 * \\
(335)\end{array}$ & $\begin{array}{c}714^{*} \\
(345)\end{array}$ & $\begin{array}{r}801 \\
(409)\end{array}$ & $\begin{array}{r}568 \\
(144)\end{array}$ & $\begin{array}{r}651 \\
(273)\end{array}$ \\
\hline & moderate & $\begin{array}{l}826 * \\
(418)\end{array}$ & $\begin{array}{l}807 * \\
(307)\end{array}$ & $\begin{array}{r}594 \\
(192)\end{array}$ & $\begin{array}{r}700 \\
(243)\end{array}$ & $\begin{array}{r}499 \\
(300)\end{array}$ & $\begin{array}{r}617 \\
(315)\end{array}$ \\
\hline & high & $\begin{array}{l}756^{*} \\
\text { (259) }\end{array}$ & $\begin{array}{l}887 * \\
(309)\end{array}$ & $\begin{array}{r}614 \\
(503)\end{array}$ & $\begin{array}{r}650 \\
(315)\end{array}$ & $\begin{array}{r}542 \\
(217)\end{array}$ & $\begin{array}{r}665 \\
(312)\end{array}$ \\
\hline
\end{tabular}

MARS; compare Table A1 and A2. $H$ is normalized to a mean $=100$ and an SD = 15 in the normative group for purposes of comparison; * indicates significance of mean differences relative to the high-risk group at the 5 percent level. The number of observations in the nine cells of the risk matrix are $(0,0: 43)$, (1,0: 42), (2,0: 36), (0,1: 45), (0,2: 32), , (1,1: 37), (2,1: 48), (1,2: 39), (2,2: 42); in total 364 observations.

In fact, these are large gaps, given that parental stimulation and responsiveness in early childhood are among the most significant resources available for the formation of competencies (see Blomeyer et al., 2010, Heckman, 2007, Heckhausen and Heckhausen, 2008, Holodynski et al., 2008, and Berger et al., 2011, among others). 


\section{A series of stage-specific competence production functions}

Equation (1) organizes the evolution of the stage-specific development process of competencies, in the spirit of the "technology of skill formation" (Cunha and Heckman, 2007). Competencies are formed by the home environment, by the competencies available from the past period, the initial organic and psychosocial conditions at birth, including the nine months in utero, and by a vector of other influences not specified in the model under investigation.

$$
\Theta_{\mathrm{t}}=f_{\mathrm{t}}\left(H_{\mathrm{t}}, \Theta_{\mathrm{t}-1}, R, E_{t}\right)
$$

In our analysis $\Theta_{t}$ is a three-dimensional vector and includes cognitive, motor, and noncognitive competencies. There are five different stages of development: infancy, toddlerhood, preschool age, elementary school age and secondary school age, termed $t$. Note that the time lag between research waves is not constant (see Figure 1). It ranges from one year and nine months (between research waves one and two) to three years (between research waves four and five). In Equation (1) competencies at time $t$ are influenced directly only by family investments in $t$ and not by the past investments. However, investments from the past exert a powerful indirect influence on competencies, due to the inclusion of past competencies in Equation (1).

$R$ is a nine-dimensional vector consisting of the nine cells of the initial organic and psychosocial risk matrix. $H_{t}$ is a scalar (it is not specific to a competence) that represents the socio-emotional home environment measured at the research wave $t$, while $E_{t}$ is a random error term, specific to each of the three competencies. The literature suggests that the estimation of competence production functions depends on the available data (see Cunha et al., 2010, Todd and Wolpin, 2003). Our estimation approach is directly 
related to the design of our epidemiological data. The data contain comprehensive sets of psychometric measures and expert ratings of the variables that are included in the theoretical model.

A further assumption on the functional form is needed for performing the econometric analysis. We assume that Equation (1) can be represented by a Cobb-Douglas function. Taking the natural logarithm of all variables (lower case letters indicate the natural logarithm), a set of three equations (2) for each research wave emerges:

$$
\theta_{\mathrm{t}, \mathrm{i}}^{\mathrm{j}}=\alpha_{0, \mathrm{t}}^{\mathrm{j}} * r+\alpha_{\mathrm{t}}^{\mathrm{h}, \mathrm{j}} \cdot h_{\mathrm{t}, \mathrm{i}}+\alpha_{\mathrm{t}}^{\mathrm{j}} \cdot \theta_{\mathrm{t}-1, \mathrm{i}}^{\mathrm{j}}+\alpha_{\mathrm{t}}^{\mathrm{k}, \mathrm{j}} \cdot \theta_{\mathrm{t}-1, \mathrm{i}}^{\mathrm{k}}+\alpha_{\mathrm{t}}^{\mathrm{l}, \mathrm{j}} \cdot \theta_{\mathrm{t}-1, \mathrm{i}}^{\mathrm{l}}+\varepsilon_{\mathrm{t}, \mathrm{i}}^{\mathrm{j}}
$$

where $j, k, l$ are indices for the competencies $I Q, M Q$ and $P . i=1, \ldots, \mathrm{N}$ is an index for the child. $r$ summarizes the nine cells of the two-dimensional risk matrix in MARS (in the form of dummy variables). According to Equation (2) competencies can be produced continuously by the home environment and the stock of competencies available from the past period. The relative contributions of $h_{t}$ and $\theta_{t-1}$ in $t$ will depend on the values of $\alpha_{t}$, the partial elasticity of the Cobb-Douglas function. While belonging to a risk group may have lasting effects on the level of competencies, the functional form allows that the competencies remain malleable in each period.

The Cobb-Douglas representation of competence formation has advantages and disadvantages. The main (and decisive) advantage arises from its flexibility and the low number of parameters to assess the role of home resources, self-productivity, and synergies in competence formation using a small data set. The main disadvantage is the assumption that the elasticity of substitution between past competencies and current home environment is one (in Cunha et al., 2010, the estimated elasticity is sometimes lower, sometimes higher than one). 
A direct assessment of critical periods is not possible, only an indirect one. The estimates are performed in each wave and the data define whether the parameters of interest are significant, allowing indirectly investigating critical periods. For instance, if the partial elasticity between the home environment and the IQ is different from zero in childhood (the first three research waves) but not different from zero in the last two research waves, then one may conclude that the childhood period is a critical period for the development of the $I Q$.

Our preferred estimates of the three competence equations are shown in Table 2. The method employed is seemingly unrelated regression (SUR) instead of OLS, to improve on efficiency. A significance level of five percent is chosen throughout the study. Each equation contains the set of dummies from the initial risk matrix, $r$, although not reported in Table 2. In the equations for cognitive and non-cognitive competencies, most indicators from the initial risk matrix lose their significance beginning at age four and a half. This does not mean that initial risk conditions no longer exert an influence on competence levels. Its continuing importance is, technically spoken, captured by the lagged competencies since the initial risk matrix significantly influences competencies in the first developmental stages.

A referee recommended reporting the correlations of residuals. The five values for each of the three possible correlations are calculated from the residuals from equation (2), called: $I Q-M Q, I Q-P, M Q-P$. For $I Q-M Q$ we find $0.42,0.53,0.16,0.19,0.30$, for $I Q-P$ 0.33, $0.40,0.08,0.26,0.05$ and for $M Q-P 0.11,0.19,0.18,0.09,-0.04$. The correlation of unmeasured factors between the $I Q$ and the $M Q$ and the $I Q$ and $P$ seem to be relatively high, whereas the correlation between the $M Q$ and $P$ seems to be relatively low. 
The parameter estimates in Table 2 indicate that $H$ is positively related to cognitive and non-cognitive competence formation at all developmental stages. However, the role of socio-emotional home resources and the level of competencies from the past period for competency formation changes in a way specific to age and competencies. The IQ is positively related to $H$ until the age of four and a half years, with an estimated partial elasticity varying between 0.27 in infancy and 0.33 in toddlerhood. At school age, the elasticity drops to 0.01 and is no longer significant.

$P$ is positively associated with $H$ at the stages of two, four and a half, and eleven years. The partial elasticity reaches its highest value at the age of two years and is still significant at the age of eleven. Although the partial elasticity between $H$ and $M Q$ is positive (with the exception of stage eleven years), it always lacks statistical significance. There appears to be a high degree of stability in interpersonal differences in the $M Q$ during the early life course. Motor abilities strongly depend on early organic and psychosocial conditions (see Blomeyer et al., 2009) and only weakly on $H$ during childhood.

During development, the socio-emotional home environment loses its strong relationship with competencies and self- and cross-productivity increases (measured by the partial elasticity of the past competencies). According to the estimates, only persistence is associated with the socio-emotional home environment in adolescence. Although Cunha et al. (2010) estimate a model with two broader developmental stages and do not include the $M Q$ some of their results are comparable with ours. For instance, selfproductivity for cognitive competencies amounts to 0.487 in their first and 0.902 in their second developmental stage (ditto p. 908, Table 1); according to our estimates, these values are 0.52 at preschool age and 0.89 at secondary school age (Table 2), which is nearly identical. 
Table 2: Econometric findings for the formation of $I Q, M Q$ and $P$ (standard errors in parentheses)

\begin{tabular}{|c|c|c|c|}
\hline & $I Q_{t}$ & $M Q_{t}$ & $P_{t}$ \\
\hline \multicolumn{4}{|c|}{$t=3$ months } \\
\hline$H_{t}$ & $0.27 *(0.07)$ & $0.05 \quad(0.06)$ & $0.04(0.07)$ \\
\hline Boys & $-0.02(0.02)$ & $-0.04 *(0.01)$ & $0.01(0.02)$ \\
\hline Adj. $\mathrm{R}^{2}$ & 0.12 & 0.15 & 0.03 \\
\hline \multicolumn{4}{|c|}{$t=2$ years } \\
\hline$H_{t}$ & $0.33^{*}(0.06)$ & $0.07 \quad(0.07)$ & $0.35 *(0.10)$ \\
\hline$I Q_{t-1}$ & $0.21 *(0.05)$ & $0.06 \quad(0.07)$ & $0.08(0.07)$ \\
\hline$M Q_{t-1}$ & $0.06 \quad(0.07)$ & $0.31 *(0.07)$ & $0.10(0.08)$ \\
\hline$P_{t-1}$ & $0.14 *(0.05)$ & $0.16 *(0.06)$ & $-0.06(0.06)$ \\
\hline Boys & $-0.06^{*}(0.02)$ & $-0.01(0.02)$ & $0.06 *(0.02)$ \\
\hline Adj. $\mathrm{R}^{2}$ & 0.34 & 0.26 & 0.16 \\
\hline \multicolumn{4}{|c|}{$t=4.5$ years } \\
\hline$H_{t}$ & $0.30 *(0.04)$ & $0.06(0.07)$ & $0.22 *(0.09)$ \\
\hline$I Q_{t-1}$ & $0.52 *(0.05)$ & $0.23 *(0.06)$ & $0.57 *(0.10)$ \\
\hline$M Q_{t-1}$ & $0.10 *(0.04)$ & $0.72 *(0.06)$ & $-0.06(0.08)$ \\
\hline$P_{t-1}$ & $0.01(0.03)$ & $0.10 *(0.04)$ & $0.16 *(0.06)$ \\
\hline Boys & $0.00(0.01)$ & $-0.03 *(0.02)$ & $-0.07 *(0.02)$ \\
\hline Adj. $\mathrm{R}^{2}$ & 0.61 & 0.58 & 0.36 \\
\hline \multicolumn{4}{|c|}{$t=8$ years } \\
\hline$H_{t}$ & $0.01(0.05)$ & $0.06(0.05)$ & $0.11(0.08)$ \\
\hline$I Q_{t-1}$ & $0.81 *(0.06)$ & $0.00(0.06)$ & $0.28 *(0.09)$ \\
\hline$M Q_{t-1}$ & $0.22 *(0.04)$ & $0.43 *(0.04)$ & $0.18 *(0.06)$ \\
\hline$P_{t-1}$ & $0.11 *(0.04)$ & $0.01(0.03)$ & $0.27 *(0.05)$ \\
\hline Boys & $0.06 *(0.03)$ & $0.01(0.01)$ & $0.00(0.02)$ \\
\hline Adj. $\mathrm{R}^{2}$ & 0.65 & 0.40 & 0.37 \\
\hline \multicolumn{4}{|c|}{$t=11$ years } \\
\hline$H_{t}$ & $-0.01(0.05)$ & $-0.00(0.05)$ & $0.19 *(0.06)$ \\
\hline$I Q_{t-1}$ & $0.89 *(0.04)$ & $0.31 *(0.05)$ & $0.19 *(0.06)$ \\
\hline$M Q_{t-1}$ & $0.13 *(0.05)$ & $0.66 *(0.05)$ & $-0.05(0.06)$ \\
\hline$P_{t-1}$ & $0.10 *(0.04)$ & $0.04(0.04)$ & $0.27 *(0.05)$ \\
\hline Boys & $0.02(0.01)$ & $0.08 *(0.02)$ & $-0.04 *(0.02)$ \\
\hline Adj. $\mathrm{R}^{2}$ & 0.72 & 0.54 & 0.35 \\
\hline
\end{tabular}

MARS; SUR regressions; 364 observations; all variables in natural logarithm;* indicates significance at the 5 percent level; all equations include a set of indicator variables from the initial risk matrix, not shown in the table. 
Differences in competence formation between boys and girls seem to exist. However, the estimated differences are stage-specific, and the positive and negative coefficients roughly add to zero over time. In the IQ equation, the coefficient for Boys is -0.06 at the age of two years, suggesting that boys lag 6 percent behind girls at that age. At school age, the coefficient for Boys changes significantly and is 0.06, suggesting that boys are ahead of girls by 6 percent. Gender-specific differences in competence development, therefore, seem to be of only moderate importance over the early life course.

Compared to our previous study, Blomeyer et al. (2009), the estimated coefficients of the partial elasticity of $H$ for competencies are moderately lower in magnitude. Our main conclusions do not change. These differences refer to the lack of scales showing mother-child-interaction (authenticity, acceptance and reactivity in the parental behaviour towards the child) and language development in the original HOME, a result that demonstrates the significant role of early mother-child interaction for development.

The relationship between family environment and children's competencies may be reciprocal. Parental responsiveness may follow complex ways. For example, parents may try to compensate for low competencies of their child through higher $H$ in order to support child development. Alternatively, parents may foster specifically the development of their children with high competencies. If parents invest in such a way, then SUR estimates of Equation (2) may be biased.

Blomeyer et al. (2009) performed two-stage least squares (2SLS) to address this endogeneity issue. The average household income per head during the first five research waves was used as an instrument. They find higher values for the estimated coefficients compared to OLS especially in childhood, although standard errors increased. For in- 
stance, the elasticity of $H$ with respect to the IQ was 2.36 (2SLS), compared to 0.55 (OLS), at three month, 1.52 (2SLS), compared to 0.38 (OLS) at two years and 0.53 (2SLS), compared to 0.38 (OLS) at 4.5 years. In later periods estimates are no longer significant. Given that the average household income per head is a valid instrument OLS estimates are biased downward. From our interpretation, OLS (or SUR) estimates therefore constitute a lower bound for the parameters of interest. We will perform the policy analysis in section 5 mainly on the basis of the OLS (or SUR) estimates in order to compare the differences between the original $H$ and the modified $H$ and mention in addition also some results from the 2SLS estimates.

\section{Preschool competencies as predictors of social outcomes at school age}

This section contributes to the empirical literature on dynamic complementarities during the early life course. The association between cognitive, motor and non-cognitive competencies at preschool age and popularity among peers, peer relations, the variety of actively followed interests, interests and math grades is investigated.

Before we turn our attention to the estimates, we briefly summarize findings from the initial risk matrix. Initial risk effects cumulate and all social adjustment scores decrease with both dimensions of the risk matrix. The difference between the non-risk and the high-risk groups amounts to roughly 25 percent. Math grades in the highest-risk group are approximately one grade lower than grades in the non-risk group. A high psychosocial risk is associated with the largest negative group effect. However, one exception is worth mentioning. If there is no psychosocial risk, organic risks seem to lose their association with regard to interests and peers. The pursuit of interests and popularity with peers is more affected by the initial psychosocial risk load and less by organic risks. 
Table 3 reports findings from SUR estimates. On the right hand side, home resources, $H$, and the level of $I Q, M Q$ and $P$ (measured at preschool age) are included. The estimates can be interpreted in terms of partial elasticity, since the (natural) logarithm was used for all variables in Table 3. Results demonstrate substantial complementarities between competencies acquired during childhood and social outcomes a child achieves at elementary school age. Cognitive and non-cognitive competencies at preschool age predict interests at primary school age, and motor and non-cognitive abilities predict peer relations. Contemporary $H$ enhances popularity among peers (peer relations) and the variety of actively followed interests (interests). Thus, children from adverse home environments seem to suffer twofold, due to poor investments in their competencies during childhood and again due to insufficient support during school age.

Table 3: The partial elasticity of $H$ and preschool competencies for social outcomes at school age (eight years assessment)

\begin{tabular}{cccc}
\hline \hline & interests & peer relations & math grades \\
\hline$H_{t}$ & $0.55^{*}$ & $0.31^{*}$ & -0.08 \\
$I Q_{t-1}$ & $0.45^{*}$ & 0.02 & $-0.75^{*}$ \\
$M Q_{t-1}$ & $0.08^{*}$ & $0.15^{*}$ & -0.08 \\
$P_{t-1}$ & $0.13^{*}$ & $0.19^{*}$ & $-0.31^{*}$ \\
Boy & -0.02 & -0.02 & $-0.11^{*}$ \\
\hline Adj. $\mathrm{R}^{2}$ & 0.58 & 0.28 & 0.20 \\
$\mathrm{~N}$ & 325 & 325 & 325 \\
\hline \hline
\end{tabular}

MARS sample; SUR regressions; all variables in natural logarithm; social competence scores from expert ratings range from 1.0 (low), 1.1, ... to 7.0 (high); grades in Germany range from 1 excellent to 6 insufficient; each equation contains indicator variables for the full initial risk matrix not displayed in the table; correlation of residuals: (interests-peer relationship 0.25; interests-math grades -0.14 ; peer relationshipmath grades -0.09$)$. ${ }^{*}$ significance at the 5 percent level.

The IQ and $P$ measured at preschool age are significantly related to better grades in math, while the $M Q$ is not. Besides the $I Q, P$ is an important predictor of achievement 
in school, which is in line with Duckworth and Seligman (2005), among others. It is worth mentioning that accruing to these estimates $H$ is not related to the grades received at age eight.

School choice in the German tracking system, as a rule, takes place after fourth grade, at the age of ten. On average, 45 per cent of the children in the MARS attend a Gymnasium at the age of 15, which is the highest-track/grammar school in Germany. In our data, more children attend the higher-track secondary school compared to the average in Baden-Wuerttemberg. The main reason is that only first-born children of German-speaking parents are enrolled in MARS, meaning that children from immigrant families with poor German language skills and later born children were not included in this sample. In terms of selection to attend a grammar school, the initial risks are still important. Among the highest-risk group, only 15 percent of the children attend the Gymnasium, compared to 74 percent in the non-risk group. Average Gymnasium attendance decreases (nearly) monotonically along the two dimensions of our risk design.

Findings from probit models predicting Gymnasium are summarized in Table 4. All probit estimates for attending the Gymnasium include a gender dummy, the home resources $H$ and $Y$ and the cognitive, motor and non-cognitive competencies. These are measured at primary school age (eight years), two years before tracking takes place. In the second specification, all indicators from the initial risk matrix are included in the estimates. IQ, $M Q$ and $P$ at primary school age are significantly related to the probability of attending the Gymnasium. The magnitude of $P$ is lower compared to the $I Q$ and higher compared to the $M Q$. If all indicators of the initial risk matrix are included, results for the other variables do not change much. Being in the highest risk group significantly lowers the probability of attending the Gymnasium (not displayed in the Table). 
Table 4: Elasticity for attending the Gymnasium at the age of 15, (standard errors in parentheses)

\begin{tabular}{|c|c|c|c|c|}
\hline \multirow[b]{2}{*}{$H_{8 \text { years }}$} & \multirow[b]{2}{*}{$1.04 *$} & \multirow[b]{2}{*}{$(0.27)$} & \multicolumn{2}{|c|}{$\begin{array}{l}\text { indicators of initial risk matrix } \\
\text { are included }^{\text {a) }}\end{array}$} \\
\hline & & & $0.98^{*}$ & $(0.28)$ \\
\hline$Y_{8 \text { years }}$ & $0.18 *$ & $(0.07)$ & $0.18^{*}$ & $(0.07)$ \\
\hline$I Q_{8 \text { years }}$ & $1.14^{*}$ & $(0.21)$ & $1.15^{*}$ & $(0.22)$ \\
\hline$M Q_{8 \text { years }}$ & $0.46^{*}$ & $(0.17)$ & $0.40 *$ & $(0.19)$ \\
\hline$P_{8 \text { years }}$ & $0.50 *$ & $(0.15)$ & $0.51^{*}$ & $(0.16)$ \\
\hline Boy & -0.00 & $(0.06)$ & -0.01 & $(0.06)$ \\
\hline Pseudo $\mathrm{R}^{2}$ & \multicolumn{2}{|c|}{0.29} & \multicolumn{2}{|c|}{0.32} \\
\hline $\mathrm{N}$ & \multicolumn{2}{|c|}{360} & \multicolumn{2}{|c|}{360} \\
\hline
\end{tabular}

MARS sample; all variables in natural logarithm; ${ }^{a)}$ this specification contains all indicators of the initial risk matrix, although not reported here; * indicates significance at the 5 percent level.

A numerical examination illustrates the importance of the stock of competencies and home resources for higher secondary school track (all values are taken from the estimates with indicators of the initial risk matrix) in the sample of children at risk. If the IQ $(P)$ at age eight increases by 10 percent, average marginal probability of attending the Gymnasium would increase by 11.5 (5.1) percent. If $H(Y)$ at school age was 10 percent higher, average marginal probability would increase by 9.8 (1.8) percent. We could not find gender-specific differences for higher secondary school attendance.

Bright children from poor households have a lower chance of entering the highest-track secondary school in the MARS data. Economic constraints (moderately) contribute to a less successful transition to the Gymnasium. Furthermore, the analysis suggests that the level of cognitive and non-cognitive competencies measured at the age of eight years is as important as the home environment at that age. 


\section{Policies to foster competencies and higher track school attendance}

In this section, initial evidence on interventions during the early life course is provided. The stage-specific estimates are used for assessing competency formation with counterfactual investments based on some preliminary thought experiments. Our intention is to highlight basic trade-offs in the timing of optimal educational policy interventions based on the MARS data, not to make statements on interventions for a representative population of children in Mannheim or Germany.

Assume that the government has two objectives. First, it aims at improving competencies at secondary school age (eleven years) and, second, at increasing the share of children attending the Gymnasium at the age of fifteen. The government either may help children to overcome constraints resulting from poor socio-emotional home resources in (early) childhood, or it may help the children later at school age through improved economic and socio-emotional home resources, or both. Assume further that the government is willing to raise $Y$ by 10 percent at one or the first four developmental stages. For the children in our sample, this would cost 66 Euros per household member per month at the first research wave 1986/1987, and 73 Euros at the fifth research wave, 1997/1998 (real Euros, base year 1995).

If we assume that there are three household members and that it is necessary to increase the annual (not only the monthly) income, $2.376 €$ would have been needed for each household in the first research wave. The overall amount of money will depend on the group of children selected. If ten percent of the 680 thousand (West-) German children born in 1988 (Statistisches Bundesamt, 2011) would have been selected (68,000 households) this would have cost 161 million $€$, a manageable amount of money. 
A 10-percent increase in $Y$ has no direct implication for the formation of cognitive, motor, and non-cognitive competencies during childhood, but an indirect one. The child will profit from an improved socio-emotional home environment, for instance from less economic stress in the family. Parents who receive a cash transfer may have more time to spend with their children and improve the socio-emotional home environment. When a poor home environment has a negative impact on earnings capabilities, cash transfers may help to overcome a vicious circle as well. For instance, research by Amarante et al. (2011) indicates that cash transfers have the potential to improve birth outcomes; Gelber and Isen (2012) show that public and family investments for children are complementary in nature.

In the data, a 10-percent increase in $Y$ is partially related with a one-to-two percent increase in $H$. This empirical relationship results from regressions of $H$ on $Y$ using the log-values of $Y$ and $H$, including a constant. Since we are not aware of other data to assess a causal relationship between $Y$ and $H$ (the reason is that $H$ is, as a rule, neither available in official statistics nor in other survey data), in what follows the lower onepercent finding is utilized for the following analysis.

We take all direct and indirect multiplier and accelerator effects from the stagedependent one-percent increase in $H$ into account in the following way. In the first step, a one-percent increase in $H$ in a specific developmental stage is associated with improved competencies (Table 2). In the second step, these higher competencies will induce further effects in the following developmental stage through synergies in competence formation (estimated elasticity of self- and cross-productivity, Table 2). The second step is repeated for each of the remaining developmental stages. 
Table 5 summarizes the results, without taking into account confidence intervals. Looking at the columns, Table 5 documents the percentage point increases of a one-percent increase in $H$ at five developmental stages during the life course. Looking at the rows, Table 5 documents the resulting effects at a specific developmental stage. There are two values in each cell of Table 5. The first value was calculated employing the findings from Table 2 while the second one (in parentheses) was calculated using the estimates from Blomeyer et al. (2009).

According to our current findings, intervention during toddlerhood is associated with the highest increase of all competencies at the age of eleven, followed by interventions during preschool age, during infancy and during school age. For instance, a one-percent gain in $H$ during toddlerhood raises the IQ by 0.72 percent at primary school age and 0.93 percent at secondary school age, taking into account all multiplier and accelerator effects.

According to our previous estimates (Table 2, second results), intervention during infancy (three months) would result in the highest increase in IQ at the age of eleven, while interventions during toddlerhood (two years) are associated with the highest increase in $P$ at the age of eleven. If instead our previous 2SLS results (Blomeyer et al., 2009) are utilized the childhood skill multiplier is much higher. For instance a one percent increase at three month (two years) increases the IQ until the age of eleven years by 3.26 (4.79), which is three to four times higher compared to the OLS results.

These findings demonstrate the eminent role of improving home resources during childhood. The childhood multiplier unfolds in any dimension of outcome that is analyzed. Further improvements in peer relationships, interests and especially school achievement 
occur. If the government should decide to increase the cash transfer to $20(30, \ldots)$ percent for specific groups, for instance for the children from the high risk group, one has to multiply the resulting values for the childhood multiplier in Table 5 by two (three, ...). This is, technically spoken, a consequence of the logarithmic model specification. General equilibrium effects are not taken into account.

Table 5: The childhood competence multiplier: direct and indirect competence effects of a one percent increase in $H$ (in percent) (in parentheses: second set of results)

\begin{tabular}{|c|c|c|c|c|c|}
\hline & & \multicolumn{4}{|c|}{ One percent increase in $H$ at stage leads to an } \\
\hline \multicolumn{2}{|l|}{$\begin{array}{c}\text { increase at } \\
\text { stage (\%) }\end{array}$} & 3 months & 2 years & 4.5 years & 8 years \\
\hline \multirow[t]{3}{*}{3 months } & $I Q$ & $0.27(0.55)$ & & & \\
\hline & $M Q$ & $0.05(0.15)$ & & & \\
\hline & $P$ & $0.04(0.28)$ & & & \\
\hline \multirow[t]{3}{*}{2 years } & $I Q$ & $0.34(0.72)$ & $0.33(0.38)$ & & \\
\hline & $M Q$ & $0.09(0.29)$ & $0.07(0.00)$ & & \\
\hline & $P$ & $0.06(0.34)$ & $0.35(0.37)$ & & \\
\hline \multirow[t]{3}{*}{4.5 years } & $I Q)$ & $0.37(0.83)$ & $0.51(0.59)$ & $0.30(0.38)$ & \\
\hline & $M Q$ & $0.13(0.44)$ & $0.23(0.14)$ & $0.06(0.04)$ & \\
\hline & $P$ & $0.10(0.46)$ & $0.59(0.67)$ & $0.22(0.50)$ & \\
\hline \multirow[t]{3}{*}{8 years } & $I Q$ & $0.42(0.96)$ & $0.72(0.82)$ & $0.58(0.74)$ & $0.03(0.19)$ \\
\hline & $M Q$ & $0.15(0.50)$ & $0.30(0.19)$ & $0.09(0.06)$ & $0.04(0.12)$ \\
\hline & $P$ & $0.13(0.55)$ & $0.73(0.84)$ & $0.37(0.76)$ & $0.13(0.43)$ \\
\hline \multirow[t]{3}{*}{11 years } & $I Q$ & $0.47(1.11)$ & $0.93(1.06)$ & $0.84(1.10)$ & $0.04(0.42)$ \\
\hline & $M Q$ & $0.17(0.56)$ & $0.42(0.31)$ & $0.20(0.19)$ & $0.11(0.26)$ \\
\hline & $P$ & $0.14(0.60)$ & $0.79(0.96)$ & $0.44(0.94)$ & $0.12(0.65)$ \\
\hline
\end{tabular}

Own calculations; all direct and indirect multiplier and accelerator effects are taken into account, see text; based on SUR estimates of equation (2) (Table 2); second set of results in parentheses: childhood multiplier calculated from Blomeyer et al. (2009, OLS Table 2). 
According to data (from Table 5, first set of results), a one-percent increase in $H$ in toddlerhood would increase the probability of entering the Gymnasium by 1.32 (1.32) percent, taking into account the improved competencies at school age, multiplied with the coefficients from the probit equation, see Table 4. This is termed policy one. An alternative intervention strategy, policy two, would be to increase $Y$ at later developmental stages. A 10-percent increase of $Y$ at age eight would directly increase the probability of attending the Gymnasium by 1.8 percent. If $H$ additionally increases by one percent, the probability of attending the Gymnasium would rise by additional 0.98 percent (Table 4). In sum, the probability of attending the Gymnasium would increase by 2.8 percent in policy two. If government aims at increasing the probability of attending the Gymnasium by 2.8 percent with policy one, it would be necessary to raise $Y$ in toddlerhood by 26 percent.

Support in childhood (policy one) and at school age (policy two) should be both successful in raising the probability of entering the Gymnasium. Supporting children at school age may help to overcome economic and socio-emotional constraints and could therefore facilitate higher secondary school choice. However, we would expect the two policies to differ in their success in improving competencies. Supporting children during childhood might be more effective, particularly in fostering cognitive competencies. As a result of dynamic complementarities in development, higher social and school competencies would emerge.

An illustration of costs and returns may be helpful for understanding the economics of alternative interventions. The cost per child for policy one stems from the 26 percent increase in $Y$ in toddlerhood. It is assumed that an annual increase is needed, which would amount to 2,575.12 € (base year 1995) for each household member (or 7,725.36 
$€$ for a household with three members). For policy two $848.84 €$ are required. Thus policy one is more expensive (1,726.28 € for each household member).

To assess the returns to higher competencies over the life cycle a sensitivity analysis was performed, based on the idea that higher cognitive and non-cognitive competencies increase labor market earnings (see Heineck and Anger, 2010 for a recent study with German data). Table 6 displays the resulting discounted life cycle gains (for either 30 or 40 years) for an average worker in Germany, given that higher competencies (remember that only policy one raises the IQ by 2.6 percent) increase annual earnings by 1,2 or 3 percent. Results suggest that policy one would create significant returns to investments in toddlerhood, if the income gains exceed one percent. For instance, if a 2.4 percent IQ gain increases annual income by two percent, the expected return (for 30 years) of policy one will be 65 percent per child $(((12,757.62 €-7,725.36 €) / 7,725.36 €)-1) * 100)$.

Table 6: Discounted lifetime earnings gains from a 1, 2, or 3 percent increase in annual earnings

\begin{tabular}{cccc}
\hline \hline lifetime & $1 \%$ & $2 \%$ & $3 \%$ \\
\hline 30 years & $6,378.81 €$ & $12,757.62 €$ & $19,136.43 €$ \\
40 years & $7,730.84 €$ & $15,461.68 €$ & $23,192.51 €$ \\
\hline \hline
\end{tabular}

Source: Own calculations based on the average of real annual labor market earning (27.264 Euro in 1997, base year 1995; taken from Gernandt and Pfeiffer, 2007, Table A2) and a discount rate of 2 percent.

A third policy derived from the present results may aim at increasing $Y$ and $H$ during the early life cycle. For instance, IQ growth until the age of eight would amount to 1.7 percent $(0.42+0.72+.055+0.01$ percent; or 2.17 percent $-0.96+0.82+0.74+0.19-$ according to our previous findings). Such an intervention would increase the probability of entering Gymnasium by 5.7 (6.6) percent, through the boosting of competencies and resources at school age. The third policy variant should be effective for improving equali- 
ty of opportunity for children with low home resources during their early life cycle. Future research should also investigate the costs and benefits of alternative policy interventions that take into account teaching. Improving the quality of teaching in secondary schools may help to improve intelligence as well (see Becker et al., 2012).

\section{Conclusions}

This paper contributes to the understanding of competence formation and the complementarities between children's early and later achievement in the early life cycle. Using unique data from an epidemiological cohort study, findings demonstrate that the initial risk matrix and the home environment are strongly related to competencies during childhood and achievement in adolescence. Policy assessments based on the regression results suggest that improving home resources during childhood should be an effective way for fostering cognitive and non-cognitive competencies. Synergies in competence formation boost social and school outcomes in adolescence as a positive side effect.

Although the evidence presented in this paper is conclusive, caveats remain and a number of research questions emerge. Since the study does not cover the population, more research is needed with more representative data. The policy analysis utilizes the empirical relationship between income per head and the socio-emotional home environment in the data, not necessarily a causal relationship. More research should be devoted to uncover causality between income, parental investment and the initial risk matrix. Our measure of the home environment summarizes more than a hundred single factors that should all be relevant for development on their own. The complex patterns of interactions between these factors need further examination to understand the various facets of the childhood multiplier for human capital formation and equality of opportunity. 


\section{References}

Amarante, V., M. Manacorda, E. Miguel, A. Vigorito (2011), Do Cash Transfers Improve Birth Outcomes? Evidence from Matched Vital Statistics, Social Security and Program Data. NBER Working Paper No. 17690, Cambridge, MA.

Bartling, B., E. Fehr, B. Fischer, F. Kosse, M. Maréchal, F. Pfeiffer, D. Schunk, J. Schupp, C. K. Spieß, G. G. Wagner (2010), Determinanten kindlicher Geduld - Ergebnisse einer Experimentalstudie im Haushaltskontext. Schmollers Jahrbuch - Journal of Applied Social Science Studies 130(3): 297-323.

Becker, M., O. Lüdtke, U. Trautwein, O. Köller, J. Baumert (2012), The Differential Effects of School Tracking on Psychometric Intelligence: Do Academic-Track Schools Make Students Smarter? Journal of Educational Psychology (in press).

Berger, E. M., F. H. Peter, C. K. Spieß (2011), Wie hängen familiale Veränderungen und das mütterliche Wohlbefinden mit der frühkindlichen Bildung zusammen. DIWVierteljahreshefte zur Wirtschaftsforschung 79 (3): 27-44.

Black, S. E., P. J. Devereux, K. Salvanes (2007), From the Cradle to the Labor Market? The Effect of Birth Weight on Adult Outcomes. Quarterly Journal of Economics 122 (1): 409-439.

Blomeyer, D., K. Coneus, M. Laucht, F. Pfeiffer (2009), Initial Risk Matrix, Home Resources, Ability Development and Children's Achievement. Journal of the European Economic Association 7(2-3): 638-648.

Blomeyer, D., M. Laucht, F. Pfeiffer, K. Reuß (2010), Mutter-Kind-Interaktion im Säuglingsalter, Familienumgebung und Entwicklung früher kognitiver und nichtkognitiver Fähigkeiten: Eine prospektive Studie. DIW-Vierteljahreshefte zur Wirtschaftsforschung 79 (3): 11-26.

Bradley, R. H. (1989), The Use of the HOME Inventory in Longitudinal Studies of Child Development. P. 191-215 in: M. H. Bornstein, N. A. Krasnegar (Eds.), Stability and continuity in mental development: Behavioral and biological perspectives. Hillsdale, New Jersey: Lawrence Erlbaum.

Bradley, R. H., R.F.Corwyn, B.M. Caldwell, L. Whiteside-Mansell, G.A. Wassermann, I.T. Mink (2000), Measuring the Home Environments of Children in Early Adolescence. Journal of Research on Adolescence 10: 247-288. 
Caldwell, B. M., R. H. Bradley (1984), Administration Manual (revised Edition) Home observation for measurement of the environment. University of Arkansas at Little Rock, Little Rock, Arkansas.

Coneus, K., M. Laucht, K. Reuß (2012), The Role of Parental Investments for cognitive and noncognitive skill formation - Evidence for the first 11 years of life. Economics and Human Biology 10: 189-209.

Cunha, F., J. J. Heckman (2007), The Technology of Skill Formation. The American Economic Review 97 (2): 31-47.

Cunha, F., J. J. Heckman, S. M. Schennach (2010), Estimating the Technology of Cognitive and Noncognitive Skill Formation. Econometrica 78 (3): 883-931.

Currie, J. (2011), Inequality at Birth: Some Causes and Consequences. American Economic Review: Papers and Proceedings 101(3): 1-22.

Duckworth, A. M., M. E. P. Seligman (2005), Self-Discipline Outdoes IQ in Predicting Academic Performance in Adolescents. American Psychological Society 16 (12): 939-944.

Gelber, A., A. Isen (2012), Children’s Schooling and Parents’ Investment in Children: Evidence from the Head Start Study. NBER Working Paper No. w17704, Cambridge, MA.

Gernandt, J., F. Pfeiffer (2007), Rising Wage Inequality in Germany. Journal of Economics and Statistics 227 (4): 358-380.

Heckhausen, H., J. Heckhausen (2008), Motivation and Action. Cambridge, Cambridge University Press.

Heckman, J. J. (2007), The Economics, Technology and Neuroscience of Human Capability Formation. Proceedings of the National Academy of Sciences 104 (3): 1322505.

Heineck, G., S. Anger (2010), The returns to cognitive abilities and personality traits in Germany. Labour Economics 17 (3): 535-546.

Holodynski, M., F. Stallmann, D. Seeger (2008), Entwicklung als soziokultureller Lernprozess: Die Bildungsbedeutung von Bezugspersonen für Kinder. P. 91-129 in: Frühkindliche Bildung und Betreuung, in T. Apolte, A. Funcke (Eds.), Nomos Verlagsgesellschaft, Baden-Baden. 
Kosse, F., F. Pfeiffer (2012), Impatience among preschool children and their mothers. Economics Letters 115: 493-495.

Laucht, M., G. Esser, M. H. Schmidt (1997), Developmental outcome of infants born with biological and psychosocial risks. Journal of Child Psychology and Psychiatry 38 (7): 843-854.

Laucht, M., M. H. Schmidt, G. Esser (2002), Motorische, kognitive und sozialemotionale Entwicklung von 11jährigen mit frühkindlichen Risikobelastungen: späte Folgen. Zeitschrift für Kinder- und Jugendpsychiatrie und Psychotherapie 30: 5-19.

Laucht, M., M.H. Schmidt, G. Esser (2004), The development of at-risk children in early life. Educational and Child Psychology 21 (1): 20-31.

Pfeiffer, F., K. Reuß (2008), Age-Dependent Skill Formation and Returns to Education. Labour Economics 15 (4): 631-646.

Rutter, M., D. Quinton (1977), Psychiatric disorder - ecological factors and concepts of causation. P. 173-187 in: Ecological factors in human development, H. McGurk (ed.). North Holland, Amsterdam.

Spieß, C. K. (2011), Ökonomie frühkindlicher Bildung und Betreuung - Aktuelle Ergebnisse aus dem deutschsprachigen Forschungsraum. DIW-Vierteljahreshefte zur Wirtschaftsforschung 79 (3): 5-10.

Statistisches Bundesamt (2011), Krankenhausstatistik, Bonn.

Todd, P. E., K. I. Wolpin (2003), On the Specification and Estimation of the Production Function for Cognitive Achievement. The Economic Journal 113: F3-F33. 
Table A1: Definition of organic risk

\begin{tabular}{|c|c|c|c|}
\hline & Items of the Risk Index & Definition & $\mathrm{N}$ \\
\hline \multicolumn{4}{|c|}{ Non-risk group: all of the items \#1 to 4} \\
\hline 1 & normal birth weight & $2.500-4.200 \mathrm{~g}$ & 118 \\
\hline 2 & normal gestational age & 38-42 weeks & 118 \\
\hline 3 & no signs of asphyxia & $\mathrm{pH}^{\mathrm{a}} \geq 7.2$ & 118 \\
\hline & & $\begin{array}{l}\text { lactic acid }{ }^{b} \leq 3.5 \mathrm{mmol} / 1 \\
\text { CTG }^{\text {a }} \text { score } \geq 8\end{array}$ & \\
\hline 4 & no surgical delivery & except elective & 118 \\
\hline \multicolumn{4}{|c|}{ Moderate-risk group: one or more of the items \#5 to \#7 } \\
\hline 5 & pre-eclampsia & $\begin{array}{l}\text { edema }^{\mathrm{b}} \\
\text { proteinuria }^{\mathrm{c}} \\
\text { hypertonia }^{\mathrm{d}}\end{array}$ & 53 \\
\hline 6 & premature birth & $\leq 37$ weeks & 151 \\
\hline 7 & signs of risk of premature birth & $\begin{array}{l}\text { premature labor } \\
\text { tocolytic treatment } \\
\text { cerclage }^{\text {e }}\end{array}$ & 43 \\
\hline
\end{tabular}

High-risk group: one or more of the items \#8 to \#10

$\begin{array}{llll}8 & \text { very low birth weight } & \leq 1.500 \mathrm{~g} & 46 \\ 9 & \text { clear case of asphyxia } & \\ & \mathrm{pH}^{\mathrm{a}} \leq 7.1 & 38 \\ & \text { lactic acid }^{\mathrm{a}} \geq 8.00 \mathrm{mmol} / \mathrm{l} & \\ & \mathrm{CTG}^{\mathrm{b}} \text { score } \leq 4 \\ & \text { treated neonatally for } \geq 7 \text { days } & \\ & & \text { seizures } \\ & \text { respiratory therapy } & \\ & \text { sepsis }\end{array}$

${ }^{\mathrm{a}}$ The $\mathrm{pH}$ value measures an acid or basic effect of a hydrous solution. For individuals, a low $\mathrm{pH}$ value and lactic acid are indicators of low blood oxygen. A CTG (cardiotocograph) measures the child's heartbeat during pregnancy and labor, and through this, pathological values also indicate a lack of blood oxygen. ${ }^{\mathrm{b}}$ An edema, also known as hydropsy, is the increase of interstitial fluid in any organ during swelling. ${ }^{\text {CProteinuria is }}$ an indicator of possible severe damage to the metabolism or of kidney disease. ${ }^{\mathrm{d}}$ Hypertonia is an indicator of a possible disease of the blood vessel system. ${ }^{\mathrm{e}}$ Cerclage is an operative sealing of the cervix to prevent premature birth. 
Table A2: Definition of psychosocial risk

\begin{tabular}{|c|c|c|c|}
\hline & Items of the Risk Index & Definition & $\mathrm{N}$ \\
\hline 1 & $\begin{array}{l}\text { Low educational level of a par- } \\
\text { ent }\end{array}$ & $\begin{array}{l}\text { Parent without completed school educa- } \\
\text { tion or without skilled job training }\end{array}$ & 74 \\
\hline 2 & Overcrowding & $\begin{array}{l}\text { More than } 1.0 \text { person per room or size of } \\
\text { housing } \leq 50 \mathrm{~m}^{2}\end{array}$ & 34 \\
\hline 3 & Parental psychiatric disorder & $\begin{array}{l}\text { Moderate to severe axis I or II disorder } \\
\text { according to DSM-III- } \mathrm{R}^{\mathrm{a}} \text { criteria (inter- } \\
\text { viewer rating, kappa }=.98 \text { ) }\end{array}$ & 76 \\
\hline 4 & $\begin{array}{l}\text { History of parental broken home } \\
\text { or delinquency }\end{array}$ & $\begin{array}{l}\text { Institutional care of a parent / more than } \\
\text { two changes of parental figures until the } \\
\text { age of } 18 \text { or history of parental delin- } \\
\text { quency }\end{array}$ & 74 \\
\hline 5 & Marital discord & $\begin{array}{l}\text { Low quality of partnership in two out of } \\
\text { three areas (harmony, communication, } \\
\text { emotional warmth) (interviewer rating, } \\
\text { kappa }=1.00 \text { ) }\end{array}$ & 43 \\
\hline 6 & Early parenthood & $\begin{array}{l}\text { Age of a parent } \leq 18 \text { years at child birth } \\
\text { or relationship between parents lasting } \\
\text { less than } 6 \text { months at time of conception }\end{array}$ & 93 \\
\hline 7 & One-parent family & At child birth & 38 \\
\hline 8 & Unwanted pregnancy & An abortion was seriously considered & 57 \\
\hline 9 & $\begin{array}{l}\text { Poor social integration and sup- } \\
\text { port of parents }\end{array}$ & $\begin{array}{l}\text { Lack of friends and lack of help in child } \\
\text { care (interviewer rating, kappa }=.71 \text { ) }\end{array}$ & 14 \\
\hline 10 & Severe chronic difficulties & $\begin{array}{l}\text { Affecting a parent lasting more than one } \\
\text { year, such as unemployment, chronic } \\
\text { disease (interviewer rating, kappa }=.93 \text { ) }\end{array}$ & 104 \\
\hline 11 & Lack of coping skills & $\begin{array}{l}\text { Inadequate coping with stressful events } \\
\text { of the past year e.g. denial of obvious } \\
\text { problems, withdrawal, resignation, over- } \\
\text { dramatization (interviewer rating, kappa } \\
=.67 \text { ) }\end{array}$ & 146 \\
\hline
\end{tabular}

a The DSM-III-R is the Diagnostic and Statistical Manual of Mental Disorders, third edition, revised form. 